\title{
Estratégia em Pequenas Empresas: uma Aplicação do Modelo de Miles e Snow
}

\author{
Fernando A. P. Gimenez \\ Cleufe Pelisson \\ Eugênio G. S. Krüger \\ Paulo Hayashi Jr.
}

\begin{abstract}
RESUMO
O presente trabalho apresenta os resultados de uma pesquisa realizada em pequenas empresas visando a identificar as estratégias competitivas adotadas pelos seus dirigentes. Para tanto utilizou-se o modelo proposto por Miles e Snow (1978) na classificação das escolhas estratégicas reportadas pelos respondentes. Dados coletados em 107 empresas da cidade de Londrina, PR, distribuídas por 8 ramos de atividades, permitiram verificar a ocorrência dos 4 tipos estratégicos propostos por Miles e Snow (1978), isto é, estratégias defensiva, analítica, prospectora e reativa. O desempenho das empresas que adotaram estratégias reativas foi menos eficaz em termos de crescimento, confirmando uma das proposições centrais do modelo. A estratégia mais freqüente foi a analítica. Não foi encontrada nenhuma diferença nas escolhas estratégicas que pudesse ser associada ao gênero do dirigente da pequena empresa.
\end{abstract}

Palavras-chaves: estratégia competitiva; pequena empresa; gênero do dirigente.

\begin{abstract}
The objective of this paper was to identify competitive strategies adopted by small firms. Miles and Snow's (1978) model of competitive strategies was used to classify reported strategic choices. Data were collected with 107 enterprises in the city of Londrina, PR, Brazil, belonging to 8 different business sectors. Results indicated that 4 types of competitive strategies were found in accordance with Miles and Snow's (1978) model. Companies' performance differed according to competitive strategies, that is, reactors were less effective in terms of growth, thus confirming one of the main model's propositions. The most frequent strategy was analytical. No differences were found that could be attributed to manager's gender.
\end{abstract}

Key words: competitive strategy; small firm; manager's gender. 


\section{INTRODUÇÃO}

Boa parte da literatura sobre administração estratégica se caracteriza pela busca de taxonomias de estratégias genéricas (Hatten e Schendel, 1977; Miller e Dess, 1993). Uma estratégia genérica pode ser vista como uma categorização ampla de escolhas estratégicas com aplicação generalizada em indústrias ou tipos de organizações (Herbert e Deresky, 1987).

A classificação proposta por Porter (1980) mostrou-se muito popular. Miller e Dess (1993) indicaram que no período compreendido entre 1986 e 1990, esta foi referenciada em metade dos trabalhos publicados no Strategic Management Journal. Porter (1980) adotou uma estrutura que inclui três estratégias competitivas genéricas, que variam na ênfase dada a duas dimensões: diferenciação x liderança de custo (vantagem estratégica); e indústria em geral x segmento particular (objetivo estratégico). A estratégia de liderança de custo se dá através da ação de empresas que procuram aumentar sua participação no mercado, buscando menores custos em relação a seus concorrentes. Diferenciação é a busca de uma vantagem competitiva através do fornecimento de produtos ou serviços que são vistos como únicos em alguma(s) qualidade(s) desejada(s) pelo consumidor. Finalmente, a estratégia de foco está baseada em dirigir os esforços da empresa para atender necessidades de um nicho específico de mercado, definido em termos geográficos ou em termos de tipo de consumidor. A estratégia de foco implica a possibilidade de aplicar uma abordagem de liderança de custo ou de diferenciação no segmento de mercado escolhido. Apesar de sua utilização generalizada, algumas limitações conceituais da tipologia proposta por Porter (1980) são afirmadas por Kotha e Vadlamani (1995), que perceberam uma diminuição na aplicação desta classificação em trabalhos mais recentes.

A principal crítica que se faz ao modelo de Porter (1980) diz respeito à sua inadequação ao ambiente empresarial atual (Mintzberg, 1988), e à sua impossibilidade de descrever todos os diferentes tipos de estratégia, isto é, as estratégias genéricas descritas por Porter (1980) não são coletivamente exaustivas (Chrisman, Hofer e Boulton, 1988).

Uma taxonomia de estratégias genéricas que tem chamado a atenção de pesquisadores em administração estratégica é a fornecida por Miles e Snow (1978). Ao contrário da classificação de Porter (1980), esta é mais abrangente e oferece melhores qualidades conceituais para um agrupamento de empresas mais preciso. A força desta taxonomia é que ela especifica relacionamentos entre estratégia, estru- 
tura e processos de uma forma que permite a identificação das organizações como universos integrados em interação com seus ambientes.

Esta taxonomia tem sido amplamente testada nos mais diversos ambientes empresariais e tem demonstrado possuir qualidades muito boas em termos de codificação e predição (Shortell e Zajac, 1990; James e Hatten, 1994). As empresas podem ser classificadas facilmente em uma de quatro categorias teóricas, e seus comportamentos podem ser previstos com base em sua classificação como defensivas, prospectoras, analíticas ou reativas.

Outro ponto que acentua a força desta taxonomia é a sua relevância para a análise do comportamento estratégico de pequenas empresas (Davig, 1986; Rugman e Verbeke, 1987). Enquanto a classificação de Porter (1980) não é muito adequada para o estudo de pequenas empresas, visto que estas seriam todas enquadradas na estratégia de foco, a taxonomia de Miles e Snow (1978) é independente do tamanho da organização.

O presente trabalho apresenta os resultados de uma pesquisa realizada em pequenas empresas visando a identificar as estratégias competitivas adotadas pelos seus dirigentes. Para tanto utilizou-se o modelo proposto por Miles e Snow (1978) na classificação das escolhas estratégicas reportadas pelos respondentes. A fim de contextualizar os resultados aqui discutidos, fazemos, em primeiro lugar, uma apresentação do conceito de estratégia e sua evolução na literatura, com ênfase nos trabalhos de Mintzberg $(1978,1990)$ e Whittington (1993). Em seguida, são expostos os principais aspectos do modelo de estratégias genéricas proposto por Miles e Snow (1978). Uma breve revisão da literatura sobre estratégia em pequenas empresas serve de pano de fundo para a discussão dos resultados obtidos nesta pesquisa.

\section{O Conceito de Estratégia}

Mintzberg (1990) identificou dez escolas de pensamento no campo da administração estratégica. Três escolas, de natureza prescritiva, têm tratado a estratégia como tentativas conscientemente deliberadas de alinhar a organização com seu ambiente, e vêem a formulação de estratégia como processo que envolve o desenho conceitual (escola do design), o planejamento formal (escola do planejamento), e o posicionamento competitivo (escola do posicionamento). Outro grupo de seis escolas é apresentado por Mintzberg (1990) como descritivo: (1) a escola empreendedora, que trata a formação de estratégia como processo visionário; (2) a escola cognitiva, que apresenta estratégia como processo mental; (3) a escola de 
aprendizagem, que considera a estratégia como o resultado de processo emergente; (4) a escola política, que enxerga a estratégia surgindo do processo de conflito e disputa por poder; (5) a escola cultural, que vê estratégia como processo ideológico; e (6) a escola ambiental, que trata a formação de estratégia como processo passivo. Finalmente, a escola de configuração procura delinear os estágios e seqüências do processo de formação de estratégia como um todo integrado.

Muito do que tem sido escrito sobre estratégia pressupõe sua conceituação como um conjunto de diretrizes conscientemente deliberadas, que orientam as decisões organizacionais. Este conceito, chamado de estratégia intencionada por Mintzberg (1978), é representativo das escolas prescritivas de pensamento estratégico. Assim, para um dos líderes da chamada escola de planejamento, estratégia é vista como processo, controlado, consciente e formal de interação entre uma empresa e seu ambiente, acompanhado pela alteração dos aspectos dinâmicos internos da empresa (Ansoff, 1979).

Apesar da existência desse tipo de estratégia ser questionada (Mintzberg, 1978), toda organização se comporta estrategicamente, mesmo sem evidência de procedimentos intencionais. Esta é a posição defendida por acadêmicos agrupados em algumas escolas descritivas (empreendedora, cognitiva, de aprendizagem e cultural). De acordo com Mintzberg (1990, p. 115) esta abordagem pode ser percebida, por exemplo, em um dos pressupostos da escola de aprendizagem: "estratégias aparecem primeiro como padrões percebidos no passado e somente mais tarde, talvez, como planos deliberados para o futuro $[\ldots]$...

Uma visão mais recente e complementar do estado atual da área de estratégia empresarial é fornecida por Whittington (1993). Este identificou quatro abordagens genéricas no processo de formação de estratégia: (1) clássica; (2) evolucionária; (3) processualista; e (4) sistêmica.

A abordagem clássica (Ansoff, 1979; Porter, 1980) apresenta a formação de estratégia como processo racional de análise deliberada, com o objetivo de maximizar a vantagem da empresa a longo prazo. Baseada em processo abrangente e detalhado de coleta de informação sobre o contexto ambiental e sobre a organização, aliado a uma análise racional, a estratégia surge de planos cuidadosamente elaborados.

Os evolucionistas (Freeman e Boeker, 1984; Hannan e Freeman, 1988), por outro lado, descartam completamente qualquer possibilidade de planejamento racional. Mudanças ambientais são consideradas impossíveis de prever, e escolhas gerenciais não têm nenhuma influência nos destinos da organização. A principal força é o mercado que seleciona os mais aptos a sobreviverem.

Os processualistas (Cyert e March, 1963; Mintzberg, 1987), embora conside- 
rem a racionalidade do planejamento imperfeita, não concordam com a fé dos evolucionistas na supremacia das forças de mercado. Diferenças individuais de interesses e limitações cognitivas impedem a emergência de planos únicos cuidadosamente elaborados. Por outro lado, imperfeições do mercado permitem a existência de estratégias não-ótimas, que emergem de um padrão de decisões passadas.

A perspectiva sistêmica (Whitley, 1991; Whittington, 1992) é menos pessimista sobre a possibilidade de o estrategista realizar uma análise racional e formular estratégias globais. Mas o contexto social das empresas torna a estratégia dependente dos sistemas sociais particulares, nos quais ela surge. Assim, o processo é concebido como racional, mas guiado por objetivos pluralísticos e não somente pela maximização de lucros. Normas individuais e culturais podem impor outros objetivos, que conflitam com a maximização de lucros.

Em resumo, Whittington (1993) propõe que duas dimensões são as diferenças fundamentais que caracterizam cada uma destas abordagens: (1) os resultados da estratégia (maximização de lucros ou resultados múltiplos); e (2) a natureza do processo de formação de estratégia (deliberado ou emergente).

As abordagens clássica e evolucionária visualizam um único resultado, surgindo do processo estratégico, isto é, a maximização de lucros é o único objetivo organizacional. Por outro lado, as abordagens sistêmica e processual consideram a existência de outros resultados no processo estratégico, tais como coalizões de poder, ou indivíduos poderosos dentro da organização restringem o atingimento da maximização de lucros (abordagem processual), enquanto o contexto social das organizações pode restringir a maximização de lucros, forçando-as a considerar a influência de valores e ideologias (abordagem sistêmica).

No que diz respeito à natureza do processo de formação de estratégia, as abordagens se agrupam de maneira diferente. As abordagens clássica e sistêmica consideram viável um processo racional de formação de estratégia. Por outro lado, as abordagens evolucionária e processual enxergam este processo governado pelo acaso, pelas limitações cognitivas e vieses inerentes ao comportamento humano.

Deve ser observado que a racionalidade proposta pelas abordagens clássica e sistêmica não é idêntica, em termos de conteúdo e implicações. Enquanto para a abordagem clássica a racionalidade na formação de estratégia é guiada pela maximização de lucros, a abordagem sistêmica considera que freqüentemente o estrategista se desvia da norma de maximização de lucros pela influência de outros interesses, tais como orgulho profissional, valores culturais, ou poder gerencial. Assim, a busca de outros objetivos em detrimento da maximização de lucros é vista como racional, embora a racionalidade possa estar disfarçada. 


\section{O Modelo de Miles e Snow}

Miles e Snow (1978) produziram uma taxonomia do que chamaram estratégias competitivas, em oposição às estratégias corporativas. Enquanto estratégias corporativas dizem respeito a decisões relacionadas ao tipo de negócio no qual a empresa deve atuar, estratégias competitivas relacionam-se ao modo como a organização compete em determinado negócio (Hambrick, 1983).

A base do trabalho de Miles e Snow (1978) está em três idéias centrais: (1) o ambiente dá forma e é formado pelas ações organizacionais - construção (enactment) do ambiente (Weick, 1979); (2) escolhas estratégicas feitas pela administração da empresa dão forma à estrutura e aos processos organizacionais (Mintzberg, 1978); e (3) processos e estrutura condicionam a estratégia (March e Simon, 1958; Fouraker e Stopford, 1968). Essas idéias dão consistência ao que tem sido denominado paradigma da escolha estratégica (Child, 1972) que, em essência, propõe: "a efetividade da adaptação organizacional depende das percepções de coalizões dominantes sobre condições ambientais e das decisões tomadas no que diz respeito ao modo como a organização lidará com estas condições" (Miles e Snow, 1978, p. 121).

O processo de construção do ambiente se materializa através de uma série de escolhas que dizem respeito a mercados, produtos, tecnologia, escala desejada de operações etc, que levam à construção de um ambiente específico pelas organizações (Weick, 1979). Por outro lado, esta construção é restringida pelo conhecimento existente de formas alternativas de organização e pelas crenças dos administradores sobre como as pessoas podem ser administradas (Miles e Snow, 1978).

De acordo com o modelo de Miles e Snow (1978), as empresas desenvolvem padrões de comportamento estratégico relativamente estáveis na busca de bom alinhamento com as condições ambientais percebidas pela administração. Os autores propõem a existência de quatro tipos de estratégias genéricas: defensiva, prospectora, analítica e reativa. Eles propuseram categorias de estratégia competitiva, que diferenciam as empresas mediante a relação estratégia/estrutura e ambiente. Estas se diferenciam nas respostas que as empresas dão aos três problemas que compõem o ciclo adaptativo: (1) problema empreendedor, com a definição de um domínio de produto/mercado; (2) problema de engenharia, com a escolha de sistemas técnicos; e (3) problema administrativo, relacionado à estrutura e aos processos organizacionais. A Figura 1 representa de forma esquemática o que Miles e Snow (1978) denominaram ciclo adaptativo. Para eles este deve ser visto como modelo geral da fisiologia do comportamento organizacional. Os três problemas, empreendedor, de engenharia e administrativo, estão intimamente 
conectados, mas a adaptação freqüentemente se inicia pela fase empreendedora, seguida pela de engenharia e, depois, pela administrativa. $O$ ciclo pode ser iniciado também pelas outras fases. Por fim, deve ser salientado que as decisões adaptativas tomadas hoje tendem a se solidificar como aspectos da estrutura de amanhã.

\section{Figura 1: O Ciclo Adaptativo}

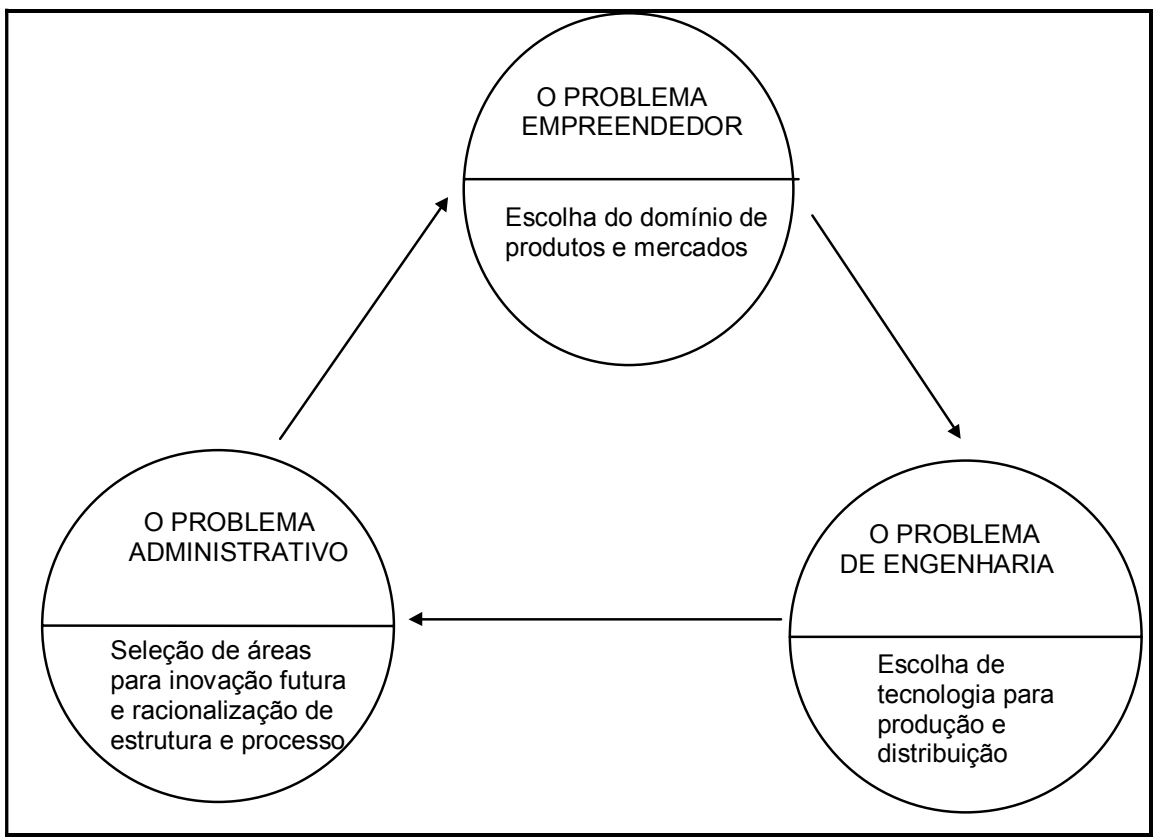

Fonte: Miles e Snow (1978, p. 24).

As duas categorias mais contrastantes são: (1) estratégia prospectora, caracterizada por elevada busca de mercados e inovação de produtos e processos; e (2) estratégia defensiva, caracterizada por estreitos domínios de produtos/mercados e por ênfase muito grande em eficiência. A terceira categoria, a analítica, pode ser vista como um híbrido das estratégias prospectora e defensiva, possuindo área de negócios central mais estável, e componente de negócios mais dinâmico, tratado de forma prospectora. Finalmente, há empresas que parecem não apresentar nenhuma relação coerente entre estratégia e estrutura, e têm uma não-estratégia, com reações impulsivas diante de eventos do ambiente, denominadas reativas.

A relação entre os quatro tipos de estratégia e o ambiente é conceito central no modelo de Miles e Snow (1978). Coerentemente com o processo de construção ambiental, as empresas defensivas irão buscar nichos de mercados onde possam 
encontrar estabilidade, mesmo nas indústrias mais dinâmicas. Organizações prospectoras, por outro lado, serão a fonte de instabilidade na indústria, por causa de sua constante geração de inovações. Hambrick (1983) descobriu que, conforme previsto pelo modelo de Miles e Snow (1978), empresas prospectoras tenderam a prosperar em ambientes dinâmicos e inovadores, pelo aproveitamento de oportunidades de crescimento, enquanto empresas defensivas prevaleceram em indústrias menos inovadoras, mais estáveis e maduras.

Dos tipos de estratégia, três foram considerados como formas estáveis de organização: defensivas, prospectoras e analíticas. Se houver alinhamento entre a estratégia escolhida e processos e estruturas organizacionais, qualquer uma destas estratégias poderá levar a empresa a ser um competidor eficaz em uma indústria em particular. O não-alinhamento entre estratégia e estrutura resultará na firma ineficaz naquela indústria, caracterizando formas instáveis de organização, que Miles e Snow (1978) denominaram empresas reativas. A inconsistência das estratégias reativas pode surgir de pelo menos três fontes: (1) falha da administração na articulação de uma estratégia organizacional viável; (2) a estratégia é articulada, mas tecnologia, estrutura e processos não estão vinculados a ela de maneira adequada; ou (3) a administração adere a uma associação particular entre estratégia e estrutura, apesar de que esta não é mais relevante nas condições ambientais.

Pelo menos um estudo conseguiu demonstrar que empresas reativas conseguiram sobrepujar os outros tipos de organizações (Snow e Hrebiniak, 1980), levando alguns estudiosos a sugerir que este tipo de estratégia pode ser adequado em ambientes com baixo grau de mudanças (Zahra e Pearce II, 1990).

Os quatro tipos de estratégia identificados por Miles e Snow (1978) se diferenciam na forma como algumas das dimensões dos problemas empreendedor, de engenharia e administrativo são resolvidas. Conant, Mokwa e Varadarajan (1990) elaboraram uma síntese das diferenças entre as categorias estratégicas, que é reproduzida no Quadro 1, a seguir.

Trabalhos mais recentes (Parnell e Wright, 1993; Beekun e Ginn, 1993; Schenk, 1994) têm trazido evidências empíricas adicionais, que confirmam a existência de quatro tipos de estratégia genérica nos mais diversos setores industriais. Além disso, esses estudos têm demonstrado também que, nos ambientes mais dinâmicos, a proporção de empresas que adotam uma estratégia prospectora é maior, enquanto as empresas defensivas são predominantes em ambientes mais estáveis. 


\section{Quadro 1: Dimensões do Ciclo Adaptativo e Características dos Tipos Estratégicos}

\begin{tabular}{|c|c|c|c|c|c|}
\hline \multirow{2}{*}{$\begin{array}{l}\text { Componentes do } \\
\text { Ciclo Adaptativo }\end{array}$} & \multirow[b]{2}{*}{ Dimensões } & \multicolumn{4}{|c|}{ TIPOS ESTRATÉGICOS } \\
\hline & & Defensiva & Prospectora & Analítica & Reativa \\
\hline \multirow{4}{*}{$\begin{array}{c}\text { Problema } \\
\text { Empreendedor e } \\
\text { Soluções }\end{array}$} & $\begin{array}{l}\text { Domínio de } \\
\text { produtos e } \\
\text { mercados }\end{array}$ & $\begin{array}{l}\text { Estreito e } \\
\text { cuidadosamente } \\
\text { focado }\end{array}$ & $\begin{array}{l}\text { Amplo e em } \\
\text { expansão } \\
\text { contínua }\end{array}$ & $\begin{array}{l}\text { Segmentado e } \\
\text { cuidadosamente } \\
\text { ajustado }\end{array}$ & $\begin{array}{l}\text { Irregular e } \\
\text { transitório }\end{array}$ \\
\hline & $\begin{array}{l}\text { Postura de } \\
\text { sucesso }\end{array}$ & $\begin{array}{l}\text { Proeminente em } \\
\text { seu mercado }\end{array}$ & $\begin{array}{l}\text { Ativa iniciação } \\
\text { de mudança }\end{array}$ & $\begin{array}{l}\text { Seguidores } \\
\text { cuidadosos de } \\
\text { mudança }\end{array}$ & $\begin{array}{l}\text { Investidas } \\
\text { oportunistas } \\
\text { e postura de } \\
\text { adaptação } \\
\end{array}$ \\
\hline & $\begin{array}{c}\text { Monitoramento } \\
\text { ambiental }\end{array}$ & $\begin{array}{l}\text { Baseado no } \\
\text { domínio e } \\
\text { cuidadoso/ } \\
\text { forte } \\
\text { monitoramento } \\
\text { organizacional }\end{array}$ & $\begin{array}{l}\text { Orientado para o } \\
\text { mercado e } \\
\text { ambiente/busca } \\
\text { agressiva }\end{array}$ & $\begin{array}{l}\text { Orientado para a } \\
\text { concorrência e } \\
\text { completo }\end{array}$ & $\begin{array}{l}\text { Esporádico } \\
\text { e dominado } \\
\text { por tópicos } \\
\text { específicos }\end{array}$ \\
\hline & Crescimento & $\begin{array}{l}\text { Penetração } \\
\text { cuidadosa e } \\
\text { avanços de } \\
\text { produtividade }\end{array}$ & $\begin{array}{l}\text { Desenvolvimen- } \\
\text { to de produtos e } \\
\text { mercados e } \\
\text { diversificação }\end{array}$ & $\begin{array}{l}\text { Penetração } \\
\text { assertiva e } \\
\text { cuidadoso } \\
\text { desenvolvimento } \\
\text { de produtos e } \\
\text { mercados }\end{array}$ & $\begin{array}{l}\text { Mudanças } \\
\text { apressadas }\end{array}$ \\
\hline \multirow{3}{*}{$\begin{array}{l}\text { Problema de } \\
\text { Engenharia e } \\
\text { Soluções }\end{array}$} & $\begin{array}{l}\text { Objetivo } \\
\text { tecnológico }\end{array}$ & $\begin{array}{l}\text { Eficiência de } \\
\text { custos }\end{array}$ & $\begin{array}{l}\text { Flexibilidade e } \\
\text { inovação }\end{array}$ & $\begin{array}{l}\text { Sinergia } \\
\text { tecnológica }\end{array}$ & $\begin{array}{l}\text { Desenvolvi- } \\
\text { mento e } \\
\text { conclusão } \\
\text { de projetos }\end{array}$ \\
\hline & $\begin{array}{l}\text { Amplitude } \\
\text { tecnológica }\end{array}$ & $\begin{array}{l}\text { Tecnologia } \\
\text { única, focal/ } \\
\text { expertise básica }\end{array}$ & $\begin{array}{l}\text { Tecnologias } \\
\text { múltiplas/ } \\
\text { avançando na } \\
\text { fronteira } \\
\end{array}$ & $\begin{array}{l}\text { Tecnologias } \\
\text { interrelacionadas/ } \\
\text { na fronteira }\end{array}$ & $\begin{array}{l}\text { Aplicações } \\
\text { tecnológicas } \\
\text { mutáveis/ } \\
\text { Fluidez } \\
\end{array}$ \\
\hline & $\begin{array}{c}\text { Anteparos } \\
\text { tecnológicos } \\
\text { (buffers) }\end{array}$ & $\begin{array}{l}\text { Programas de } \\
\text { manutenção e } \\
\text { padronização }\end{array}$ & $\begin{array}{l}\text { Habilidades de } \\
\text { pessoal técnico/ } \\
\text { diversidade }\end{array}$ & $\begin{array}{l}\text { Incrementalismo } \\
\text { e sinergia }\end{array}$ & $\begin{array}{l}\text { Habilidade } \\
\text { de } \\
\text { experimen- } \\
\text { tar e } \\
\text { improvisar } \\
\text { soluções }\end{array}$ \\
\hline \multirow{4}{*}{$\begin{array}{c}\text { Problema } \\
\text { Administrativo e } \\
\text { Soluções }\end{array}$} & $\begin{array}{l}\text { Coalizão } \\
\text { dominante }\end{array}$ & $\begin{array}{l}\text { Finanças e } \\
\text { Produção }\end{array}$ & $\begin{array}{l}\text { Marketing e } \\
\text { P\&D }\end{array}$ & $\begin{array}{l}\text { Pessoal de } \\
\text { Planejamento }\end{array}$ & $\begin{array}{l}\text { Soluciona- } \\
\text { dores de } \\
\text { problemas }\end{array}$ \\
\hline & Planejamento & $\begin{array}{l}\text { De dentro para } \\
\text { fora/ dominado } \\
\text { por controle }\end{array}$ & $\begin{array}{l}\text { Busca de } \\
\text { problemas e } \\
\text { oportunidades/ } \\
\text { perspectiva de } \\
\text { programas ou } \\
\text { campanhas } \\
\end{array}$ & $\begin{array}{l}\text { Abrangente com } \\
\text { mudanças } \\
\text { incrementais }\end{array}$ & $\begin{array}{l}\text { Orientado } \\
\text { por crises e } \\
\text { desarticula- } \\
\text { do }\end{array}$ \\
\hline & Estrutura & $\begin{array}{l}\text { Funcional/ } \\
\text { Autoridade de } \\
\text { linha }\end{array}$ & $\begin{array}{l}\text { Por produtos } \\
\text { e/ou mercados }\end{array}$ & $\begin{array}{l}\text { Dominada por } \\
\text { assessores/ } \\
\text { orientada por } \\
\text { matriz }\end{array}$ & $\begin{array}{l}\text { Autoridade } \\
\text { formal } \\
\text { rígida/ } \\
\text { desenho } \\
\text { operacional } \\
\text { solto } \\
\end{array}$ \\
\hline & Controle & $\begin{array}{l}\text { Centralizado, } \\
\text { formal e } \\
\text { ancorado em } \\
\text { aspectos } \\
\text { financeiros }\end{array}$ & $\begin{array}{l}\text { Desempenho no } \\
\text { mercado/ } \\
\text { volume de } \\
\text { vendas }\end{array}$ & $\begin{array}{l}\text { Métodos } \\
\text { múltiplos/ } \\
\text { cálculos de } \\
\text { riscos } \\
\text { cuidadosos/ } \\
\text { contribuição de } \\
\text { vendas }\end{array}$ & $\begin{array}{l}\text { Evitar } \\
\text { problemas/ } \\
\text { resolver } \\
\text { problemas } \\
\text { remanescen- } \\
\text { tes }\end{array}$ \\
\hline
\end{tabular}




\section{Pequena Empresa e Estrategia}

A literatura sobre estratégia em pequenas empresas é altamente influenciada por duas grandes abordagens: uma de natureza econômica e outra de natureza empreendedora. A perspectiva econômica tem sido predominante na área, especialmente até meados da década de oitenta. Por outro lado, uma tendência mais recente, a empreendedora, está surgindo com o reconhecimento da possível importância da influência do comportamento individual sobre o processo de formação e implantação de estratégia. Esta nova abordagem estuda a associação entre características pessoais do dirigente e o processo de administração estratégica da pequena empresa (Bamberger, 1983; Miller e Toulouse, 1986; Rice Jr. e Lindecamp, 1989).

Os esforços de pesquisa no campo de administração estratégica em pequenas empresas se têm mostrado pouco conclusivos em muitos aspectos. Um dos únicos pontos em que parece haver uma convergência dos estudos diz respeito à natureza do processo de planejamento estratégico em pequenas empresas, que tem sido descrito como incompleto, não-estruturado, irregular, esporádico, reativo, informal e pouco sofisticado (Shuman, 1975; Sexton e Dahle, 1976; Sexton e Van Auken, 1982).

Assim como na literatura dedicada às grandes empresas, os estudos analisados revelam uma abordagem fragmentada do processo de formação de estratégia em pequenas empresas. A maioria deles utiliza conceitos pouco abrangentes no estudo do conteúdo de estratégias. Não se pode escapar de uma sensação de confusão, quando se pretende resumir as conclusões dos estudos empíricos no paradigma econômico. A associação entre planejamento estratégico e desempenho da empresa não foi firmemente demonstrada. A falta de uniformidade nos conceitos adiciona mais ingredientes nesta confusão. A operacionalização dos conceitos de estratégia, planejamento estratégico e desempenho da empresa tem sido tão diversificada que abordagens integrativas não são possíveis.

Davig (1986) estudou as estratégias adotadas por pequenas empresas em indústrias maduras, usando a taxonomia proposta por Miles e Snow (1978). Dados obtidos com uma amostra de 60 empresas indicaram que firmas de estratégias prospectoras e defensivas atingiram melhor desempenho em termos de crescimento de lucros, enquanto as reativas apresentaram a pior performance. $\mathrm{O}$ desempenho de empresas analíticas se situou entre os resultados de reativas e os outros dois tipos. Diferenças em crescimento em vendas não foram estatisticamente significativas, apesar de estarem na mesma direção. Em oposição às conclusões de Smith, Guthrie e Chen (1986), o tamanho da empresa não pareceu estar associado 
com desempenho, mas as empresas maiores tenderam a ser analíticas ou prospectoras. Este estudo demonstrou a existência dos quatro tipos de estratégia em uma amostra de pequenas empresas.

Rugman e Verbeke (1987) se opuseram ao uso do modelo de Porter (1980) no contexto de pequenas empresas e defenderam a adoção das proposições de Miles e Snow (1978). Eles exemplificam a aplicação deste modelo com um estudo na indústria de distribuição de eletricidade canadense. Uma amostra de empresas foi estudada, e a estratégia dominante foi a prospectora. Muitas empresas foram identificadas como reativas, algumas como defensivas. Contrariamente ao que seria esperado, nenhuma estratégia analítica foi encontrada.

\section{Método da Pesquisa}

Um levantamento nos cadastros da Prefeitura Municipal de Londrina e da Companhia de Desenvolvimento de Londrina, PR, permitiu a identificação da população de pequenas empresas do município. Estas foram definidas como empresas de até 100 empregados no momento da coleta de dados.

Foram escolhidos 8 ramos de atividade econômica, que representassem, de forma equilibrada, as empresas da cidade de Londrina. Para isto foram verificadas as atividades econômicas mais significativas e que contassem com expressivo número de pequenas empresas. Os setores escolhidos distribuíram-se entre empresas industriais, comerciais e prestadoras de serviços com empresas dos seguintes ramos específicos: comércio de produtos para informática; indústria de alimentação; supermercados; indústria química; indústria de confecções; lojas de vestuário; agências de turismo; e indústria metalúrgica. O objetivo de se escolher empresas comerciais, prestadoras de serviços e industriais foi verificar se haveria alguma diferença de proporções de estratégias entre os setores.

Informações coletadas por telefone permitiram localizar 406 pequenas empresas distribuídas nestes ramos de atividade econômica. Definiu-se um critério de amostragem de $25 \%$ da população de empresas. Em sorteio aleatório foram contatadas mais de 100 empresas que, após algumas ponderações, ficaram distribuídas conforme os dados da Tabela 1 . 
Tabela 1: Amostragem

\begin{tabular}{|l|c|c|c|c|}
\hline \multicolumn{1}{|c|}{ Ramo de atividade } & População & Tamanho da amostra & $\%$ & \\
\hline Comércio de produtos para informática & 47 & 13 & 27,6 & \\
\hline Indústria de alimentação & 85 & 24 & 28,2 & \\
\hline Supermercados & 51 & 14 & 27,4 & \\
\hline Indústria química & 50 & 15 & 30,0 & \\
\hline Indústria de confecções & 67 & 17 & 25,4 & \\
\hline Lojas de vestuário & 60 & 7 & 11,7 & \\
\hline Agências de turismo & 20 & 11 & 55,0 & \\
\hline Indústria metalúrgica & 26 & 6 & 23,1 & \\
\hline Total & 406 & 107 & 26,3 & \\
\hline
\end{tabular}

Após o contato telefônico inicial, foram agendadas entrevistas com o dirigente principal de cada empresa. Na entrevista, os respondentes foram solicitados a fornecer dados demográficos da empresa e deles mesmos, e tiveram de preencher um questionário adaptado de Conant, Mokwa e Varadarajan (1990), cujo objetivo é identificar a estratégia adotada pelo dirigente da empresa, de acordo com o modelo de Miles e Snow (1978). Este questionário é composto de 11 questões que procuram reproduzir as dimensões que descrevem as escolhas estratégicas que compõem o modelo descrito. Para cada questão são apresentadas 4 alternativas de resposta. Através de um modelo de escolha forçada, o respondente deve indicar a alternativa que melhor se aproxima da maneira pela qual a empresa se comporta em cada uma das 11 dimensões. O critério de classificação das empresas em defensivas, analíticas, prospectoras ou reativas, é o de maior número de respostas associado a uma destas alternativas. Quando houve empate entre alternativas analíticas, defensivas e prospectoras, a estratégia resultante foi classificada como analítica. No caso de empate com alternativas reativas, a estratégia foi classificada como reativa.

O grau de confiabilidade do questionário foi averiguado com a realização de uma análise de clusters de casos. Nesta análise criaram-se variáveis dummy para cada uma das alternativas de resposta às 11 questões, atribuindo-se o valor 1 à presença de resposta e o valor $\mathbf{0}$ à ausência. Considerando que o modelo que o questionário representa indica existirem quatro diferentes tipos de estratégia, usouse o método de Ward para efetuar a análise, forçando pela identificação de 4 clusters. Os casos foram identificados pela estratégia atribuída segundo o critério acima explicado. A composição dos clusters foi a seguinte:

. Cluster 1: 14 defensivas; 31 analíticas; 3 reativas; 1 prospectora.

. Cluster 2: 15 reativas; 1 analítica. 
. Cluster 3: 19 prospectoras.

. Cluster 4: 13 analíticas; 4 prospectoras; 1 reativa; 1 defensiva.

A análise dos clusters permite verificar que 79,2\% das empresas prospectoras foram agrupadas em um cluster isolado, enquanto $78,9 \%$ das reativas se agruparam com uma empresa analítica. O cluster 1 foi formado, majoritariamente, por $93,3 \%$ das empresas defensivas e $68,8 \%$ das analíticas. O último cluster agrupou $28,8 \%$ das analíticas com $16,6 \%$ das prospectoras. Se considerarmos que a estratégia analítica, é um híbrido entre as estratégias prospectora e defensiva, e levando em conta o critério de atribuição da classificação de analítica aos casos de empate entre defensiva ou prospectora e analítica, as composições mistas destes dois clusters têm sentido. Se denominarmos o cluster 1 de defensivo, o número 2 de reativo, o número 3 de prospector e o número 4 de analítico, 59,2\% dos casos estão classificados como empresas que adotam estratégias semelhantes, o que indica um grau aceitável de confiabilidade do questionário.

\section{Resultados}

Os dados foram coletados em 107 empresas distribuídas pelos seguintes ramos de atividades: serviços de informática; indústria de alimentação; supermercados; indústria química; indústria de confecções; lojas de vestuário; agências de turismo; e indústria metalúrgica.

Na Tabela 2 observa-se que a maioria das empresas pesquisadas são maduras, ou seja, $67,3 \%$ têm idade superior a 5 anos. As empresas mais jovens, até 2 anos, representaram uma pequena amostra $(4,7 \%)$. O número médio de empregados das empresas pesquisadas foi de 7,7, com um máximo de 58 pessoas.

\section{Tabela 2: Idade das Empresas}

\begin{tabular}{|l|c|c|}
\hline \multicolumn{1}{|c|}{ Idade } & Freqüência & $\%$ \\
\hline Até 1 ano & 2 & 1,9 \\
\hline 1 a 2 anos & 3 & 2,8 \\
\hline 2 a 5 anos & 30 & 28,0 \\
\hline Mais de 5 anos & 72 & 67,3 \\
\hline
\end{tabular}

Foram homens $66 \%$ dos entrevistados. Das pessoas entrevistadas a maioria situa-se numa faixa etária que varia entre 31 e 50 anos, ou seja, 64,5\% estão 
compreendidas nesse intervalo. São poucos os empresários cuja educação formal se restringe apenas ao primeiro grau. A maioria dos entrevistados possui o segundo grau completo $(40,4 \%)$. O número de dirigentes com curso superior também foi significativo, isto é, $28,4 \%$.

Nos últimos 5 anos quase dois terços das empresas cresceram, enquanto apenas $10,3 \%$ delas diminuíram seu volume de atividades. Por outro lado, $25,2 \%$ das empresas mantiveram-se estáveis no mercado, conforme se depreende dos dados na Tabela 3.

\section{Tabela 3: Crescimento nos Últimos Cinco Anos}

\begin{tabular}{|l|c|c|}
\hline \multicolumn{1}{|c|}{ Histórico } & Freqüência & $\%$ \\
\hline Crescimento & 69 & 64,4 \\
\hline Estabilidade & 27 & 25,2 \\
\hline Decréscimo & 11 & 10,3 \\
\hline
\end{tabular}

Entre as empresas que cresceram, apenas 22 delas apresentaram crescimento acima de $50 \%$, ou seja, a grande maioria obteve crescimento médio ou moderado. As faixas de grande representatividade são as de 21 a 50\% (44,9\% das respostas), conforme evidenciado na Tabela 4.

\section{Tabela 4: Grau de Crescimento}

\begin{tabular}{|l|c|c|}
\hline \multicolumn{1}{|c|}{ Crescimento } & Frequência & $\%$ \\
\hline Até $10 \%$ & 7 & 10,1 \\
\hline 11 a $20 \%$ & 7 & 10,1 \\
\hline 21 a $30 \%$ & 14 & 20,3 \\
\hline 31 a $50 \%$ & 17 & 24,6 \\
\hline 51 a $70 \%$ & 10 & 14,5 \\
\hline Acima de $70 \%$ & 12 & 17,4 \\
\hline Não responderam & 2 & 2,9 \\
\hline Total & 69 & 100,0 \\
\hline
\end{tabular}

Como pode ser visto na Tabela 5, a seguir, e de acordo com o proposto por Miles e Snow (1978), os quatro tipos de estratégia competitiva foram adotados pelos dirigentes de pequenas empresas no presente estudo. A estratégia analítica foi a mais freqüente, com $44,8 \%$ das empresas pesquisadas. Em segundo lugar, vem a estratégia prospectora, com $22,4 \%$, seguida pela reativa, com $17,7 \%$, e defensiva, em último lugar, com 14,9\%. 


\section{Tabela 5: Estratégias Adotadas}

\begin{tabular}{|l|c|c|}
\hline \multicolumn{1}{|c|}{ Estratégia } & Freqüência & $\%$ \\
\hline Analítica & 48 & 44,8 \\
\hline Defensiva & 16 & 14,9 \\
\hline Prospectora & 24 & 22,4 \\
\hline Reativa & 19 & 17,7 \\
\hline
\end{tabular}

Em quase todos os ramos de atividades, os quatro tipos estratégicos propostos por Miles e Snow (1978) estiveram presentes (vide Tabela 6). Todavia, no ramo de comércio de produtos para informática, não se identificou nenhum caso de estratégia defensiva, enquanto no ramo de supermercados não se encontrou nenhuma empresa prospectora. Alguns estudos indicaram diferenças na proporção de três estratégias associadas ao dinamismo do ambiente competitivo. Este resultado pode ser explicado, talvez, pela diferença de dinamismo entre os dois ramos de atividade. O setor de supermercados é relativamente mais estável, menos propenso a inovações estratégicas, portanto com menor número de empresas prospectoras. Por outro lado, o ramo de comércio de produtos para informática, por ser relativamente mais dinâmico, mais propenso a inovações estratégicas, pode não ser um ambiente favorável a estratégias defensivas.

Tabela 6: Estratégia Competitiva por Ramo de Atividade

\begin{tabular}{|l|l|l|l|l|}
\cline { 2 - 5 } \multicolumn{1}{c|}{} & \multicolumn{4}{c|}{ ESTRATÉGIA } \\
\hline Ramo de atividade & Defensiva & Prospectora & Analítica & Reativa \\
\hline Comércio de produtos para informática & 0 & 6 & 6 & 1 \\
\hline Indústria de alimentação & 4 & 6 & 11 & 3 \\
\hline Supermercado & 3 & 0 & 8 & 3 \\
\hline Indústria química & 3 & 3 & 6 & 3 \\
\hline Indústria de confecções & 2 & 4 & 7 & 4 \\
\hline Lojas de vestuário & 1 & 1 & 4 & 1 \\
\hline Agência de turismo & 2 & 2 & 5 & 2 \\
\hline Indústria metalúrgica & 1 & 2 & 1 & 2 \\
\hline
\end{tabular}

A comparação entre o desempenho das empresas e a estratégia adotada indicou que as empresas reativas apresentaram o pior desempenho relativo, ou seja, 31,6\% delas diminuíram suas atividades. Os outros três tipos de estratégia apresentaram desempenho melhor, pois menos de $10 \%$ delas apresentaram diminuição nas atividades. Isto vem confirmar a proposta de Miles e Snow (1978), quando afirmam que as estratégias defensivas, analíticas e prospectoras são mais eficazes. $\mathrm{Na}$ Tabela 7 detalham-se os resultados relativos à estratégia e ao desempenho das empresas. 
Tabela 7: Estratégia e Desempenho

\begin{tabular}{|l|c|c|c|}
\hline \multicolumn{1}{|c|}{ Estratégia } & Crescimento & Estabilidade & Decréscimo \\
\hline Defensiva & 9 & 6 & 1 \\
\hline Analítica & 33 & 12 & 3 \\
\hline Prospectora & 18 & 5 & 1 \\
\hline Reativa & 9 & 4 & 6 \\
\hline Total & 69 & 27 & 11 \\
\hline
\end{tabular}

Analisando o número médio de empregos, vemos que as empresas prospectoras foram as que empregavam mais pessoas, em média, no momento da pesquisa $(9,5)$. Por outro lado, as reativas foram as que apresentaram a menor média $(4,9)$, enquanto as defensivas e as analíticas apresentaram resultados médios de 5,8 e 7,3 respectivamente. Se considerarmos o número de empregados como fator de desempenho (crescimento), confirmamos novamente a menor eficácia das estratégias reativas. Isto se confirma pela verificação do número máximo de empregados por tipo de estratégia. Para as reativas este foi de 12 pessoas, enquanto para as prospectoras foi de 58, para as defensivas 23 , e para as analíticas 27 .

$\mathrm{Na}$ Tabela 8 monstramos a relação entre a idade das empresas e a estratégia adotada. Conforme se menciona anteriormente, dois terços das empresas podem ser consideradas maduras (mais de 5 anos de existência). Destas, 45,8\% adotaram estratégia analítica; $22,2 \%$, uma estratégia prospectora; $16,7 \%$, uma estratégia defensiva, e 15,3\% seguiram a estratégia reativa.

\section{Tabela 8: Estratégia e Idade das Empresas}

\begin{tabular}{|l|c|c|c|}
\hline \multicolumn{1}{|c|}{ Estratégia } & - de 2 anos & Entre 2 e 5 anos & + de 5 anos \\
\hline Defensiva & - & 4 & 12 \\
\hline Analítica & 2 & 13 & 33 \\
\hline Prospectora & 2 & 6 & 16 \\
\hline Reativa & 1 & 7 & 11 \\
\hline Total & 5 & 30 & 72 \\
\hline
\end{tabular}

Finalmente, verificamos se houve alguma diferença entre homens e mulheres empreendedoras, no que diz respeito à escolha de estratégias na condução de seus negócios. Os dados na Tabela 9, na seqüência, nos permitem afirmar que, para a amostra em estudo, não houve nenhuma associação entre gênero do respondente e estratégia da empresa, uma vez que as proporções entre as 4 alternativas são praticamente iguais para os 2 grupos. Além disso, percebeu-se também que o desempenho das empresas não está associado ao gênero do dirigente. 


\section{Tabela 9: Estratégia, Gênero e Desempenho}

\begin{tabular}{|c|c|c|c|c|c|}
\hline & \multicolumn{4}{|c|}{ GÊNERO } \\
\hline & & \multicolumn{2}{|c|}{ MASCULINO } & \multicolumn{2}{|c|}{ FEMININO } \\
\hline & & $\mathrm{N}$ & $\%$ & $\mathrm{~N}$ & $\%$ \\
\hline \multirow{4}{*}{ ESTRATÉGIA } & DEFENSIVA & 11 & 15,5 & 5 & 13,8 \\
\hline & ANALÍTICA & 31 & 43,7 & 17 & 47,2 \\
\hline & PROSPECTORA & 16 & 22,5 & 8 & 22,2 \\
\hline & REATIVA & 13 & 18,3 & 6 & 16,6 \\
\hline \multirow{3}{*}{ DESEMPENHO } & CRESCIMENTO & 45 & 63,3 & 24 & 66,6 \\
\hline & ESTABILIDADE & 18 & 25,3 & 9 & 25,0 \\
\hline & DECRÉSCIMO & 8 & 11,3 & 3 & 8,3 \\
\hline
\end{tabular}

\section{Consideraçóes Finais}

Este estudo demonstrou a possibilidade de aplicação do modelo de Miles e Snow (1978) na investigação das escolhas estratégicas adotadas por pequenas empresas em diversos ramos de atividade. Conforme se evidenciou na discussão do modelo, qualquer ambiente empresarial contém organizações que competem de forma semelhante, permitindo seu agrupamento em quatro tipos distintos de estratégia: defensiva, analítica, prospectora e reativa. Neste estudo esta proposição foi confirmada.

Os resultados apresentados trazem argumentos adicionais que ajudam a derrubar a especulação feita por Smith, Guthrie e Chen (1986), no sentido de que a tipologia de Miles e Snow (1978) poderia ser vista como estágios seqüenciais de desenvolvimento estratégico, ou seja, estratégias defensivas estariam associadas a pequenas empresas, e estratégias prospectoras a empresas maiores. Tamanho e idade da empresa podem estar associados: $66,7 \%$ das empresas pesquisadas têm mais de 5 anos de idade, o que indica que todos os tipos estratégicos do modelo em estudo são opções viáveis para pequenas empresas.

Outra proposição do modelo que foi confirmada diz respeito à menor eficácia da estratégia reativa, quando comparada com as demais. Conforme foi evidenciado, através de dois critérios de desempenho, as empresas que adotaram estratégias defensivas, prospectoras e analíticas, em termos gerais de crescimento e, mais especificamente, em termo de número de empregos gerados, apresentaram melhor desempenho do que as empresas classificadas como reativas.

A possível associação entre dinamismo ambiental e proporção de estratégias foi 
também demonstrada neste estudo. Embora o pequeno número de respondentes em cada ramo de atividade impeça afirmações categóricas, os resultados deste estudo parecem indicar que a proporção de tipos estratégicos pode variar com o dinamismo ambiental. Nenhuma medida de dinamismo ambiental foi utilizada nesta pesquisa; todavia o fato de não ter sido encontrada nenhuma empresa prospectora no ramo de supermercados e nenhuma empresa no ramo de comércio de produtos para informática, parece indicar que os resultados deste estudo estão na mesma direção de outros estudos que lidaram com a questão do dinamismo ambiental (Hambrick, 1983).

Por fim, o estudo demonstrou que o gênero do dirigente não está associado, de forma significativa, à escolha de uma estratégia competitiva, e tampouco ao desempenho das organizações estudadas. Este resultado, de novo, confirma as proposições do modelo de Miles e Snow (1978), que afirmam que somente características de experiência profissional estão associadas à estratégia adotada.

Não se pode deixar de mencionar algumas limitações deste estudo. Em primeiro lugar, os dados sobre desempenho das organizações refletem apenas a percepção dos respondentes; não houve verificação direta de dados mais objetivos, como por exemplo, evolução de faturamento e lucratividade. No entanto o critério do número de empregados serve como atenuante desta limitação.

Por outro lado, o questionário de identificação das estratégias adotadas, embora tenha sido testado com sucesso em outros estudos (Rickards e Gimenez, 1994), foi originalmente escrito na língua inglesa. Sua versão para o português foi testada e aperfeiçoada por meio de uma série de 6 entrevistas pilotos. O teste de confiabilidade que fizemos indicou cerca de $60 \%$ de correção na classificação das empresas, grau aceitável, mas que pode ser melhorado.

\section{RefERÊnCIAS Biblográficas}

ANSOFF, H. I.

Strategic management.

London : Macmillan, 1979.

\section{BAMBERGER, I.}

Value systems, strategies and the performance of small and medium-sized firms. European

Small Business Journal, v. 1, n. 4, p. 25-39, 1983.
BEEKUN, R. I.;

GINN, G. O.

Business strategy and interorganizational linkages within the acute care hospital industry : an expansion of the Miles and Snow typology. Human Relations, v. 46, n. 11, p. 12911318, 1993. 
CHILD, J.

Organisational structure, environment and performance : the role of strategic choice. Sociology, v. 5, p. 01-22, 1972.

CHRISMAN, J. J.;

HOFER, C. W.;

BOULTON, W. R.

Toward a system of classifying business strategies. Academy of Management Review, v. 13, p. 413-428, 1988.

CONANT, J. S.;

MOKWA, M. P.;

VARADARAJAN, P. R.

Strategic types, distinctive marketing competencies and organisational performance : a multiple measures-based study. Strategic Management Journal, v. 11, p. 365-383, 1990.

CYERT, R. M.;

MARCH, J. G.

A behavioural theory of the firm. Englewood Cliffs, NJ : Prentice-Hall, 1963.

DAVIG, W.

Business strategies in smaller manufacturing firms. Journal of Small Business Management, v. 24, n. 1, p. 38-46, 1986.

FOURAKER, L. E.; STOPFORD, J. M.

Organisational structure and the multinational strategy.

Administrative Science

Quarterly, v. 13, p. 47-64, 1968.

FREEMAN, J.;

BOEKER, W.

The ecological analysis of business strategy. California Management Review, v. 26, n. 3, p. 73-86, 1984.

HAMBRICK, D. C.

Some tests of the effectiveness and functional attributes of Miles and Snow's strategic types. Academy of Management Journal, v. 26, n. 1, p. 05-26, 1983.

HANNAN, M. T.;

FREEMAN, J.

Organisational ecology. Boston, MA: Harvard University Press, 1988.

HATTEN, K. J.;

SCHENDEL, D. E.

Heterogeneity within and industry : firm conduct in the U.S. brewing industry. The Journal of Industrial Economics, v. 26, n. 2, p. 97-113, 1977.

HERBERT, T. T.;

DERESKY, $\mathrm{H}$.

Generic strategies : an empirical investigation of typology validity and strategy content. Strategic Management Journal, v. 8, p. 135-147, 1987. 
JAMES, W. L.;

HATTEN, K. J.

Further evidence on the validity of the self typing paragraph approach : Miles and Snow strategic archetypes in banking. Strategic Management Journal, v. 16, n. 2, p. 161-168, 1994.

KOTHA, S.;

VADLAMANI, B. L.

Assessing generic strategies : an empirical investigation of two competing typologies in discrete manufacturing industries. Strategic Management Journal, v. 16, n. 1, p. 75-83, 1995.

MARCH, J. G.;

SIMON, H. A.

Organisations. New York : John Wiley \& Sons, 1958.

MILES, R. E.;

SNOW, C. C.

\section{Organizational strategy,} structure and process. New York : McGraw-Hill, 1978.

\section{MILLER, A.;}

DESS, G. G.

Assessing Porter's (1980) model in terms of its generalizability, accuracy and simplicity. Journal of Management Studies, v. 30, n. 4, p. 553-585, 1993.
MILLER, D.;

TOULOUSE, J-M.

Strategy, structure, CEO personality and performance in small firms. American Journal of Small Business, v. 10, n. 3, p. 47-62, 1986.

MINTZBERG, H.

Patterns in strategy formation. Management Science, v. 24, $\mathrm{n}$. 9, p. 934-948, 1978.

Crafting strategy. Harvard Business Review, v. 65, n. 4, p. 65-75, 1987.

Generic strategies : toward a comprehensive framework. Advances in Strategic Management, v. 5, p. 01-67, 1988.

Strategy formation schools of thought. In: FREDRICKSON, J. W. (Ed.). Perspectives on strategic management. Boston : Ballinger, 1990. p. 105-235.

PARNELL, J. A.;

WRIGHT, $P$.

Generic strategy and performance : an empirical test of the Miles and Snow typology. British Journal of Management, v. 4, n. 1, p. 29-36, 1993.

PORTER, M. E.

Competitive strategy. New York : Free Press, 1980. 
RICE JR, G. H.;

LINDECAMP, D. P.

Personality types and business success of small retailers. Journal of Occupational Psychology, v. 62, n. 2, p. 177-182, 1989.

RICKARDS, T.;

GIMENEZ, F. A. P.

Cognitive style and strategic choice : an exploratory study. Working paper, Manchester Business School, 1994.

RUGMAN, A. M.;

VERBEKE, A.

Does competitive strategy work for small business? Journal of Small Business and Entrepreneurship, v. 5, n. 3, p. 45-50, 1987.

\section{SCHENK, U. W.}

Technology strategies and the Miles \& Snow typology : a study of the biotechnology industries.

R\&D Management, v. 24, n. 1, p. 57-64, 1994.

SEXTON, D. L.;

VAN AUKEN, P.

Prevalence of strategic planning in small business. Journal of Small Business and Entrepreneurship, v. 20, n. 3, p. 20-26, 1982.
SEXTON, T. M.;

DAHLE, R. D.

Factors affecting long-range planning in the small business firm. Marquette Business Review, v. 20, n. 4, p. 158-165, 1976.

SHORTELL, S. M.;

ZAJAC, E. J.

Perceptual and archival measures of Miles and Snow's strategic types : a comprehensive assessment of reliability and validity. Academy of Management Journal, v. 33, n. 4, p. 817-832, 1990.

SHUMAN, J. C.

Corporate planning in small companies : a survey. Long Range Planning, v. 8, n. 5, p. 81-90, 1975.

SMITH, K. G.;

GUTHRIE, J. P.;

CHEN, M-J.

Miles and Snow's typology of strategy, organisational size and organisational performance. Academy of Management Proceedings, p. 45-49, 1986.

SNOW, C. C.;

HREBINIAK, L. G.

Strategy, distinctive competence, and organisational performance. Administrative Science Quarterly, v. 25, p. 317-335, 1980. 
WEICK, K. E.

The social psychology of organizing. Reading, MA : Addison Wesley, 1979.

WHITLEY, R.

The social construction of business systems in East Asia. Organization Studies, v. 12, n. 1, p. 01-28, 1991.

WHITTINGTON, R.

Putting Giddens into action : social systems and managerial agency. Journal of Management Studies, v. 29, n. 6, p. 693-712, 1992.

What is strategy and does it matter? London : Routledge, 1993.

ZAHRA, S. A.;

PEARCE II, J. A.

Research evidence on the MilesSnow typology. Journal of Management, v. 16, n. 4, p. 751768, 1990. 